\title{
ISOLATION REARING IN THE RAT DISRUPTS THE HIPPOCAMPAL RESPONSE TO STRESS
}

\author{
S. MUCHIMAPURA, A. J. FULFORD, R. MASON and C. A. MARSDEN* \\ School of Biomedical Sciences, University of Nottingham Medical School, Queen's Medical Centre, Nottingham NG7 2UH, UK
}

\begin{abstract}
Both human schizophrenia and the effects of isolation rearing in rats produce deficits in hippocampal and cortical functioning. This study was concerned with identifying changes associated with altered neuronal function in the rat hippocampus following isolation rearing. Rats were isolated from weaning at 21 days postnatal for 6 weeks and the hippocampal sensitivity to isolation rearing and stress were studied using c-fos immunohistochemistry and in vivo microdialysis. Isolation rearing altered neuronal activity measured by Fos-like immunoreactivity in the specific brain areas as measured by either increased or reduced expression. Basal neuronal activity in the ventral CA1 hippocampus in isolationreared rats was notably higher compared to group-reared rats but markedly lower Fos-like immunoreactivity was found in the central and basolateral nuclei of the amygdala. Exposure to stress produced differential effects on neuronal activity in isolation-reared rats between the dorsal and ventral hippocampus, with increased Fos-like immunoreactivity in the dorsal hippocampus but lower Fos-like immunoreactivity in the ventral hippocampus compared to group-reared rats. These results indicate that isolation rearing may alter the relationship between hippocampal neuronal function in the dorsal and ventral hippocampus. An in vivo microdialysis study showed that systemically administered parachloroamphetamine $(2.5 \mathrm{mg} / \mathrm{kg}$, i.p.) enhanced extracellular 5-hydroxytryptamine $(5-\mathrm{HT})$ in the dorsal hippocampus in groupreared but not in isolation-reared rats. Restraint stress had no effect on hippocampal extracellular 5-HT in group-reared rats but reduced levels in isolation-reared rats during the period of restraint. Inescapable mild footshock produced a marked increase in extracellular hippocampal 5-HT in group-reared but not isolation-reared rats.

Overall the results provide extensive evidence that isolation rearing alters presynaptic 5-HT hippocampal function and that the neuronal response to stress is altered by isolation. Isolation rearing in the rat alters hippocampal function, including the serotonergic system, leading to changes in neurotransmitter systems in other brain areas. These changes may model aspects of human neurodevelopmental disorders such as schizophrenia. (C) 2002 IBRO. Published by Elsevier Science Ltd. All rights reserved.
\end{abstract}

Key words: social isolation, c-fos, restraint stress, mild footshock, serotonin.

Stress results from a change in the external or internal environment of the cell. A specific set of genes called immediate early genes, such as proto-oncogene c-fos

*Corresponding author. Tel.: +44-115-9709487; fax: +44-1159709259.

E-mail address: charles.marsden@nottingham.ac.uk

(C. A. Marsden)

Abbreviations: 5-HT, 5-hydroxytryptamine; ABL, basolateral amygdala nucleus; ABM, basomedial amygdala nucleus; ACe, central amygdala nucleus; ALa, lateral amygdala nucleus; $\mathrm{AMe}$, median amygdala nucleus; ANOVA, analysis of variance; AP, anteroposterior; DAB, 3,3'-diaminobenzidine; dCA1, CA1 field of dorsal hippocampus; dCA2, CA2 field of dorsal hippocampus; dCA3, CA3 field of dorsal hippocampus; dDG, dentate gyrus, dorsal part; DLPAG, periaqueductal grey, dorsolateral nuclei; DPAG, periaqueductal grey, dorsal nuclei; EDTA, ethylenediaminetetra-acetate; FC, frontal cortex; HPLC, high-performance liquid chromatography; -LI, -like immunopositive nuclei; LPAG, periaqueductal grey, lateral nuclei; PAG, periaqueductal grey; PCA, parachloroamphetamine; $\mathrm{PVN}$, paraventricular nucleus thalamus; vCA1, CA1 field of ventral hippocampus; vCA2, CA2 field of ventral hippocampus; vCA3, CA3 field of ventral hippocampus; vDG, dentate gyrus, ventral part; VPAG, periaqueductal grey, ventral nuclei. and c-jun, are rapidly transcribed in an early period after the cell is exposed to stressors. The expression of immediate early genes indicates that the cell has been activated and thus might be due to direct activation by the stressors or modulation of a particular set of gene expressions to cope with the stress situation (Senba and Ueyama, 1997). Since the last decade c-fos has been used as a marker of neuronal activation in living animals after exposure to various kind of stimuli or stressors (Morgan et al., 1987; Sagar et al., 1988; Ceccatelli et al., 1989). Previous studies on restraint stress demonstrated a pattern of c-fos expression in the forebrain and brainstem (Ceccatelli et al., 1989; Schreiber et al., 1991; Arnold et al., 1992; Senba et al., 1993; Imaki et al., 1995; Stone and Zhang, 1995; Bonaz and Rivest, 1998). C-fos expression after restraint stress mainly occurs in the forebrain, including the lateral septum, medial preoptic area, median amygdala nucleus (AMe), parvocellular region of paraventricular hypothalamus and disparate cortical regions, with scattered cells found in the dorsal part of supraoptic nucleus. In addition, restraint also induces c-fos expression in the brainstem, including the central grey, lateral parabrachial nucleus, locus coeruleus, nucleus of tractus solitarius and other nuclei containing catecholaminergic or serotonergic neurones (Senba and 
Ueyama, 1997). It is widely known that stress is one of the underlying causes of many mental disorders, especially depression and schizophrenia (Stanford and Salmon, 1993). As isolation-reared rats have been shown to have certain behavioural and anatomical characteristics of these disorders, it was important to study the effect of isolation rearing on neuronal activity following processive stress.

5-Hydroxytryptamine (5-HT) is a central neurotransmitter with an important role in the adaptation to stress as various kinds of stressors elicit increases in extracellular 5-HT in various brain areas (Chaouloff, 1993; Rueter et al., 1997). Interestingly, there remains a debate about the nature of the specific effect of stress on changes in extracellular 5-HT. One group believes that all stressors induce an increase in extracellular 5-HT but this is not specific to the activation of 5-HT neurones in either the dorsal raphe nucleus or the median raphe nucleus (Linthorst et al., 1995). In contrast, another group believes that there are site-dependent changes in extracellular 5-HT levels depending on the nature of the stressors (Kirby et al., 1995, 1997; Adell et al., 1997).

Fulford and Marsden (1998) reported enhanced release of serotonin in isolation-reared rats in the nucleus accumbens. This is in contrast with an earlier study showing reduction of 5-HT function in the ventral hippocampus in isolation-reared rats in response to a novel environment (elevated plus maze) (Bickerdike et al., 1993). These results may imply that isolation rearing differentially affects the function of serotonergic neurones in various brain areas under aversive conditions.

The aim of the present study was to determine whether isolation rearing altered neuronal activity in response to stress by comparing the levels of Fos protein in various brain regions induced by acute restraint stress $(10 \mathrm{~min})$ in group- and isolation-reared rats. The study also further investigated the changes in serotonergic function in isolation-reared rats by studying the effects of serotonergic drugs, restraint stress and mild footshock on 5-HT presynaptic function in the dorsal hippocampal using in vivo microdialysis.

\section{EXPERIMENTAL PROCEDURES}

\section{Animals}

Male Lister-hooded rats (bred at Queen's Medical Centre, Nottingham, UK) were obtained at weaning (21-25 days postnatal) and housed either singly or in groups for 6 weeks (six per group) in plastic cages which were lined with sawdust. The size of the cage for isolation-reared rats was $41 \times 26 \times 20 \mathrm{~cm}$ whereas for group-reared rats the size was $52 \times 32 \times 20 \mathrm{~cm}$. Both groupand isolation-reared rats were kept on a 12-h light/dark cycle (lights on at $07.00 \mathrm{~h}$ ) and maintained at temperature $22 \pm 0.5^{\circ} \mathrm{C}$. Food and water were available ad libitum. All experiments were performed under UK Home Office Project Licence 40/1955 following ethical review. All procedures were performed in a manner to minimise discomfort and the number of animals used.

\section{Restraint stress and Fos immunocytochemistry}

At 6 weeks post-weaning rats were subjected to a 10-min restraint stress ( $n=4$ animals/group), which was performed between 8.30 and $9.00 \mathrm{~h}$, using adjustable individual restraint tubes (transparent Perspex restraint tube with $0.5 \mathrm{~cm}$ wall thickness, $6.5 \mathrm{~cm}$ diameter, $31 \mathrm{~cm}$ total length and $24 \mathrm{~cm}$ adjustable length). Tubes could be adjusted to the size of the animal so that it was unable to move in the tube. At the end of the stress session, the rats were placed in their home cages until killed at $90 \mathrm{~min}$ after the onset of restraint stress. Control animals were freely moving animals, that remained in their home cage throughout the $90 \mathrm{~min}$. After $90 \mathrm{~min}$ all animals were anaesthetised with sodium pentobarbital (Sagatal, $100 \mathrm{mg} / \mathrm{kg}$ ) and transcardial perfusion was carried out using $0.9 \%$ saline $100 \mathrm{ml}$ to remove the blood, followed by perfusion of filtered $4 \%$ paraformaldehyde in $0.1 \%$ sodium phosphate buffer $(\mathrm{pH} 7.4) 100 \mathrm{ml}$. The brains were removed, left overnight in $4 \%$ paraformaldehyde in $0.1 \%$ sodium phosphate buffer and sections $(100 \mu \mathrm{m})$ cut on a vibratome (Model 752; Campden Instruments, UK). The sections were placed into 24-well plates (one slice per well) which contained $500 \mu \mathrm{l}$ immunobuffer in each well. The sections were incubated for $30 \mathrm{~min}$ in $1 \% \mathrm{H}_{2} \mathrm{O}_{2}$ in immunobuffer, washed two times with immunobuffer ( 5 min per wash), following by incubation in $2 \%$ normal rabbit serum $(500 \mu \mathrm{l})$ for $15 \mathrm{~min}$ and then incubated with $500 \mu \mathrm{l}$ fos antibody (dilution 1:2000 in immunobuffer and normal rabbit serum, OA-11-824A, Sigma Genosys, Pampisford, UK) for $48 \mathrm{~h}$. After $48 \mathrm{~h}$ incubation, the fos antibody was removed and the sections washed three times with immunobuffer $(10 \mathrm{~min} / \mathrm{wash})$. The second antisheep biotinylated antibody (Vector Laboratories, Peterborough, UK, dilution 1:200 in immunobuffer) $500 \mu \mathrm{l}$ was added to each well to incubate for $24 \mathrm{~h}$ and then removed. The sections were washed three times with immunobuffer (10 $\mathrm{min} / \mathrm{wash})$, incubated with avidin-biotin-peroxidase complex (Vectastain $\mathrm{ABC}$ kit, Vector Laboratories) for $1-3 \mathrm{~h}(500 \mu \mathrm{l} / \mathrm{well})$ following by a wash (three times) with $50 \mathrm{mM}$ Tris buffer (10 min/wash). The final incubation was with $3,3^{\prime}$-diaminobenzidine (DAB) in $0.1 \mathrm{M}$ phosphate buffer for $10 \mathrm{~min}(500 \mu \mathrm{l} / \mathrm{well})$ and then with DAB solution containing $0.1 \% \mathrm{H}_{2} \mathrm{O}_{2}\left(20 \mu \mathrm{l} / \mathrm{well}\right.$ of $\left.3 \% \mathrm{H}_{2} \mathrm{O}_{2}\right)$ to develop the brown colour. Finally the sections were washed three times with $50 \mathrm{mM}$ Tris buffer $(10 \mathrm{~min} /$ wash $)$ and attached to gelatine subbed slides and allowed to air dry for $24 \mathrm{~h}$. The slides were dehydrated in $100 \%$ ethanol for $15 \mathrm{~min}$, defaded in histoclear for $15 \mathrm{~min}$, and the coverslips were mounted with styrolite.

Density of Fos-like immunopositive nuclei (Fos-LI) in each brain area was obtained using the coronal sections and co-ordinates from bregma using anteroposterior (AP) co-ordinates (Paxinos and Watson, 1986) frontal cortex (FC) 2.70, dorsal hippocampus, dentate gyrus (DG), thalamic paraventricular nucleus (PVN), amygdala -3.3, and periaqueductal grey (PAG) -6.04. Sub-regions within the hippocampus (e.g. CA1 and $\mathrm{CA} 2, \mathrm{CA} 3$ and dentate gyrus) were identified using anatomical markers on the sections. C-fos-positive nuclei were counted using a modified Olympus microscope. The total numbers of c-fos-positive nuclei were divided by the reference area $\left(\mathrm{mm}^{2}\right)$ to calculate the cell density per unit area. The reference area was calculated from the graticule (grid size $\times$ number of grids, $13.5 \times 13.5 \mathrm{~mm}^{2} \times 15$ ) divided by the magnification of the lens at the same magnification used for tracing the c-fos-positive nuclei $(\times 110)$.

Reference area $\left(\mathrm{mm}^{2}\right)=\frac{\text { graticule }\left(\mathrm{mm}^{2}\right)}{\text { magnification }}{ }^{2}$

Cell density $\left(\right.$ cells $\left./ \mathrm{mm}^{2}\right)=\frac{\text { total number of cells }(\text { cells })}{\text { reference area }\left(\mathrm{mm}^{2}\right)}$

The mean value from each animal was obtained from both left and right sides of the brain hemispheres. Statistical significance was analysed with a one-way analysis of variance (ANOVA) followed by a Bonferroni's multiple comparison test or a twotailed unpaired $t$-test. The increment ratio in the stress response in isolation- and group-reared rats was calculated by subtracting the control from the stress value and dividing the increment value from isolates by that from group-reared rats. 


\section{In vivo microdialysis}

Concentric microdialysis probes were made from semipermeable renal dialysis tubing (reconstituted cellulose) with a molecular weight cut off point of $20000(220 \mu \mathrm{m}$ outer diameter, 180 $\mu \mathrm{m}$ inner diameter). Dialysis probes were connected prior to surgery to the infusion pump via a liquid swivel system with continuous perfusion with artificial cerebrospinal fluid (composition in $\mathrm{mM}: \mathrm{NaCl} 125.0, \mathrm{NaHCO}_{3} 27.0, \mathrm{KCl} 2.5, \mathrm{NaH}_{2} \mathrm{PO}_{4}$ $\left.0.5, \mathrm{Na}_{2} \mathrm{HPO}_{4} 1.2, \mathrm{Na}_{2} \mathrm{SO}_{4} 0.5, \mathrm{MgCl}_{2} 1.0, \mathrm{CaCl}_{2} \cdot 2 \mathrm{H}_{2} \mathrm{O} 1.0\right)$ at a flow rate of $2 \mu \mathrm{l} / \mathrm{min}$.

After 6 weeks, post-weaning rats were implanted with microdialysis probes in the left dorsal hippocampus under anaesthesia. Anaesthesia was induced using halothane $(3 \%)$ in a $\mathrm{N}_{2} \mathrm{O}: \mathrm{O}_{2}$ mixture $(1: 5)$ and the rats were placed in a stereotaxic frame fitted with blunt ear bars. Anaesthesia was maintained during surgery with $2 \%$ halothane. The skull was exposed and a small hole drilled to allow the implantation of the dialysis probe into the left dorsal hippocampus (co-ordination: AP -4.3 , mediolateral +3 relative to bregma, dorsoventral -2.8 relative to dura according to the atlas of Paxinos and Watson, 1986). Therefore, in this study samples of extracellular 5-HT were obtained largely from the CA1 region of the left hippocampus. The probe was fixed to the skull with two skull screws and dental cement. The open incision was sutured and sprayed with antibacterial powder (Betadine, Seton Healthcare, Banbury, UK) and plastic wound dressing (Nobecutane, Astra Pharmaceuticals, Loughborough, UK). The rats were allowed to recover for at least $16 \mathrm{~h}$ prior to experimentation.

\section{Experimental protocol for in vivo microdialysis}

Separate groups ( $n=6$ per group) of animals were used for each of the three studies.

Effect of parachloroamphetamine $(2.5 \mathrm{mg} / \mathrm{kg})$. After the 16-h recovery period, seven basal samples prior to the injection of parachloroamphetamine (PCA) $2.5 \mathrm{mg} / \mathrm{kg}$ (i.p.) and then eight further samples at 20-min intervals were collected into Eppendorf vials $(0.5 \mathrm{ml})$ containing $5 \mu \mathrm{l}$ perchloric acid $(0.4 \%)$ and immediately snap frozen and stored at $-70^{\circ} \mathrm{C}$ until assay.

Acute restraint stress. After the collection of seven basal samples the rat was exposed to restraint stress for $30 \mathrm{~min}$ using the clear Perspex restraint tube. One dialysis sample was collected during the time that the rat was in the restraint tube. At the end of the period of restraint, another eight dialysis samples were collected. All the restraint stress sessions were performed between 10.30 and $12.00 \mathrm{~h}$.

Mild footshock. After the collection of three basal samples, the rats were exposed to mild footshock $(0.4 \mathrm{~mA}$ for $1 \mathrm{~s}$ every min for $10 \mathrm{~min})$ using a testing box $(25 \times 25 \times 38 \mathrm{~cm})$ and six samples were further collected. All the footshock sessions were performed between 10.30 and $12.00 \mathrm{~h}$.

\section{HPLC-electrochemical detection analysis of dialysis samples}

5-HT in dialysates was quantified using reverse-phase-ionpair high-performance liquid chromatography (HPLC) with electrochemical detection. A solvent delivery pump (2400 p.s.i. at $0.3 \mathrm{ml} / \mathrm{min})$ was used to circulate mobile phase $(0.15 \mathrm{M}$ $\mathrm{Na}_{2} \mathrm{HPO}_{4}, 1.0 \mathrm{mM}$ EDTA, $0.5 \mathrm{mM}$ sodium octanylsulphonate, $12 \%$ methanol, $\mathrm{pH}$ 3.6). Samples were injected onto a column $(100 \times 2 \mathrm{~mm}$ inner diameter, Phenomenex, Macclesfield, UK) packed with $3 \mu \mathrm{m}$ ODS $_{\mathrm{c} 18}$ material (Hichrom, Reading, UK) via a Rheodyne 7125 sample injector. 5-HT was measured electrochemically using a glassy carbon working electrode set at $+0.60 \mathrm{~V}$ maintained by a $\mathrm{Ag} / \mathrm{AgCl}$ reference electrode (Antec VT-03 cell, Leyden, The Netherlands). Changes in potential were detected by an Antec amperometric detector linked to an integrator (Spectra-physics Chromjet, Pennsylvania, USA) for

Table 1. Effect of restraint stress on the expression of c-fos in the various brain areas in control group and control isolation-reared rats that remained in their home cage and those given $10 \mathrm{~min}$ restraint stress

\begin{tabular}{|c|c|c|c|c|}
\hline \multirow[t]{2}{*}{ Brain area } & \multicolumn{2}{|l|}{ Control } & \multicolumn{2}{|c|}{ Restraint stress } \\
\hline & Group & Isolation & Group & Isolation \\
\hline \multicolumn{5}{|l|}{ Frontal cortex } \\
\hline Fc areal & $51.4 \pm 10.1$ & $57.5 \pm 11.9$ & $93.5 \pm 8.8 * *$ & $153.3 \pm 13.6^{++* * *}$ \\
\hline Fc area2 & $171.5 \pm 12.4$ & $192.0 \pm 19.87$ & $197.5 \pm 10.5$ & $298.8 \pm 15.0^{+++* * *}$ \\
\hline \multicolumn{5}{|c|}{ Dorsal hippocampus } \\
\hline CA1 & $1.4 \pm 0.2$ & $1.2 \pm 0.1$ & $1.9 \pm 0.2^{*}$ & $1.7 \pm 0.3^{*}$ \\
\hline $\mathrm{CA} 2$ & $2.0 \pm 0.2$ & $1.9 \pm 0.2$ & $2.3 \pm 0.2$ & $2.8 \pm 0.3^{*}$ \\
\hline $\mathrm{CA} 3$ & $1.7 \pm 0.1$ & $1.4 \pm 0.1$ & $2.2 \pm 0.2 *$ & $1.7 \pm 0.1^{*}$ \\
\hline DG & $1.4 \pm 0.1$ & $1.2 \pm 0.2$ & $1.5 \pm 0.1$ & $1.7 \pm 0.2 *$ \\
\hline \multicolumn{5}{|c|}{ Ventral hippocampus } \\
\hline CA1 & $1.5 \pm 0.2$ & $2.9 \pm 0.3^{+}$ & $2.1 \pm 0.1 * *$ & $2.8 \pm 0.2$ \\
\hline $\mathrm{CA} 2$ & $1.4 \pm 0.1$ & $2.4 \pm 0.3$ & $2.3 \pm 0.4^{*}$ & $2.6 \pm 0.2$ \\
\hline CA3 & $1.3 \pm 0.1$ & $1.6 \pm 0.2$ & $1.3 \pm 0.2$ & $1.5 \pm 0.1$ \\
\hline DG & $0.9 \pm 0.1$ & $1.5 \pm 0.2$ & $1.1 \pm 0.1$ & $1.4 \pm 0.1$ \\
\hline \multicolumn{5}{|l|}{ Periaqueductal grey } \\
\hline DPAG & $5.1 \pm 0.6$ & $4.2 \pm 0.5$ & $8.4 \pm 1.3^{*}$ & $7.5 \pm 2.3^{*}$ \\
\hline DLPAG & $7.0 \pm 1.0$ & $5.0 \pm 0.3$ & $8.6 \pm 1.1$ & $7.4 \pm 1.4^{*}$ \\
\hline LPAG & $9.3 \pm 1.2$ & $6.5 \pm 0.5$ & $8.7 \pm 1.0$ & $8.8 \pm 1.2 *$ \\
\hline VPAG & $7.5 \pm 1.6$ & $7.1 \pm 1.5$ & $9.3 \pm 1.7$ & $8.1 \pm 0.4$ \\
\hline \multicolumn{5}{|l|}{ Amygdala } \\
\hline $\mathrm{ABM}$ & $9.0 \pm 1.0$ & $6.8 \pm 1.6$ & $9.9 \pm 1.2$ & $10.8 \pm 1.3^{*}$ \\
\hline $\mathrm{ABL}$ & $2.8 \pm 0.3$ & $2.0 \pm 0.2^{+}$ & $2.8 \pm 0.2$ & $2.4 \pm 0.5$ \\
\hline ALa & $7.1 \pm 0.6$ & $5.3 \pm 1.2$ & $6.7 \pm 0.8$ & $6.2 \pm 1.1$ \\
\hline $\mathrm{ACe}$ & $10.8 \pm 1.3$ & $11.1 \pm 1.9$ & $11.1 \pm 1.9$ & $7.7 \pm 1.3^{*}$ \\
\hline $\mathrm{AMe}$ & $10.2 \pm 1.0$ & $9.8 \pm 1.5$ & $7.4 \pm 1.0$ & $8.9 \pm 1.3$ \\
\hline Entorhinal cortex & $8.4 \pm 0.9$ & $8.9 \pm 0.1$ & $10.1 \pm 0.1$ & $10.4 \pm 1.4^{*}$ \\
\hline PVN thalamus & $9.9 \pm 0.1$ & $8.8 \pm 0.5$ & $11.1 \pm 0.1$ & $12.5 \pm 1.0^{*}$ \\
\hline
\end{tabular}

Values are mean of Fos-LI density (cells $/ \mathrm{mm}^{2}$ ) \pm S.E.M. obtained from both hemispheres, $n=4$ animals $/$ group. ${ }^{+++} P<0.001,{ }^{++} P<0.01$, ${ }^{+} P<0.05$ significantly different between group- and isolation-reared rats and ${ }^{* * *} P<0.001,{ }^{* *} P<0.01,{ }^{*} P<0.05$ significant effect produced by restraint compared with controls from the same rearing condition (one-way ANOVA, Bonferroni's multiple comparison). 
the display of chromatograms. The minimum level of detection for 5 -HT was $2 \mathrm{fmol}$.

\section{Statistical analysis}

Statistical analyses were performed on the absolute values for extracellular 5-HT $(\mathrm{fmol} / 20 \mu \mathrm{l})$. Extracellular 5-HT was compared following stress or PCA in group-reared versus isolation-reared rats using two-factor ANOVA (time, treatment) with repeated measure using a Bonferroni post test. With the PCA and footshock data, the analysis was divided into two phases: pre- and post-drug or footshock. With restraint stress the levels of 5-HT during restraint in group- and isolationreared rats were analysed using a $t$-test and following restraint using a two-factor ANOVA as above. All data are presented as mean \pm S.E.M.

\section{RESULTS}

The effect of isolation rearing on the basal Fos-like immunoreactivity expression in brain regions

The effects of isolation rearing and restraint stress on the expression of Fos-LI were measured in 21 brain areas. Non-restrained isolation-reared rats showed a significant difference in Fos-LI in certain brain areas, specifically in the hippocampus (vCA1) and the basolateral amygdala (ABL), compared with non-restrained groupreared rats (Table 1).

Control non-restrained isolation-reared rats had a significantly higher density of Fos-LI in the vCA1 compared to control non-restrained group-reared rats $(P<0.05)$. But the ABL isolation-reared rats had significantly lower Fos-LI densities than those in nonrestrained group-reared rats (Table $1 ; P<0.05$ ).

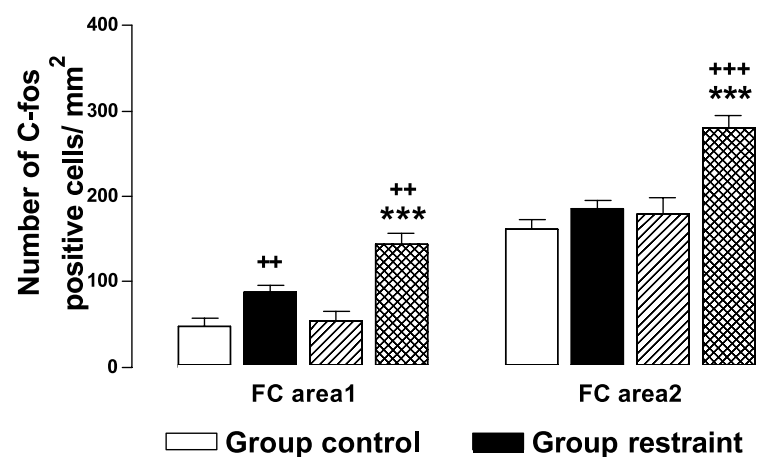

एسm Isolation control Isolation restraint

Fig. 1. The effect of restraint stress on the expression of c-fos-positive cells in the frontal cortex obtained from control group and control isolation-reared rats that remained in their home cage compared to those given 10 min restraint. Values are mean Fos-LI density $\left(\right.$ cells $\left./ \mathrm{mm}^{2}\right) \pm$ S.E.M. obtained from both hemispheres, $n=4$ animals/group. ${ }^{+++} P<0.001,{ }^{++} P<0.01$ significant difference between group- and isolation-reared rats and $* * * P<0.001$, ${ }^{* *} P<0.01$ significant effect produced by restraint compared with controls from the same rearing condition (one-way ANOVA, unpaired $t$-test).
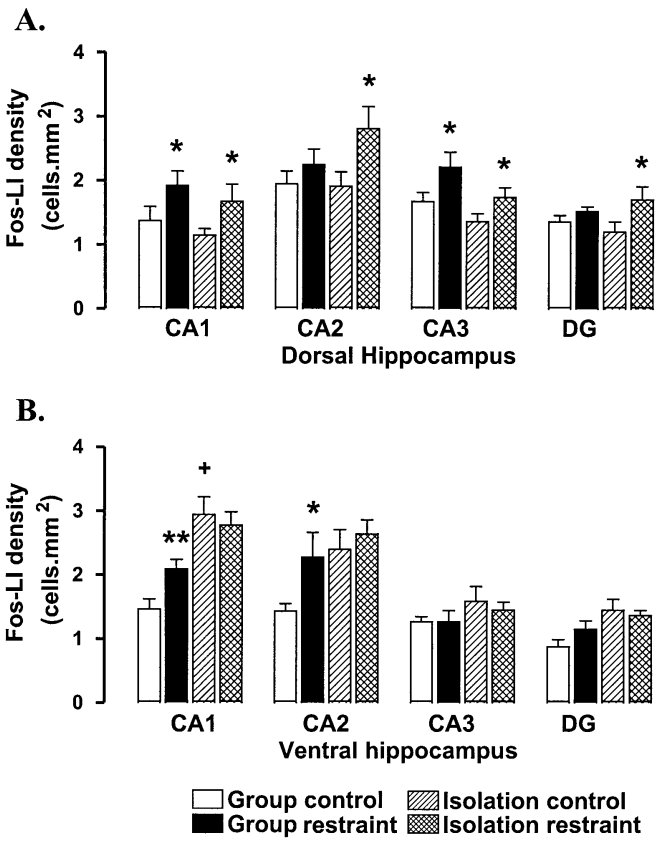

Fig. 2. The effect of restraint stress on the expression of c-fos in (A) dorsal hippocampus and (B) ventral hippocampus obtained from control group- and control isolation-reared rats that remained in their home cage and those given $10 \mathrm{~min}$ restraint. Values are mean Fos-LI density $\left(\right.$ cells $\left./ \mathrm{mm}^{2}\right) \pm$ S.E.M. obtained from both hemispheres, $n=4$ animals/group. ${ }^{* *} P<0.01, * P<0.05$ significantly different from control from the same rearing condition, ${ }^{+} P<0.05$ significant difference between group- and isolationreared rats without restraint (one-way ANOVA, post test; Bonferroni's multiple comparison test).

The expression of Fos-like immunoreactivity in the brain regions following $10 \mathrm{~min}$ restraint stress

Restraint stress induced an increase in Fos-LI expression in several of the brain areas studied. In group-reared rats the expression of Fos-LI was significantly increased by restraint in the FC area 1, specific areas of the hippocampus [dorsal (d) CA1, dCA3, ventral (v) CA1, vCA2] and DPAG (Table 1). In the FC area 2, dCA1, dDG, vCA3, entorhinal cortex dorsolateral (DL) PAG, lateral (L) PAG, VPAG, entorhinal cortex, PVN thalamus and the amygdaloid nucleus, Fos-LI density levels were unaffected by restraint when compared with control nonrestrained group-reared rats (Table 1).

Isolation-reared rats given restraint stress for $10 \mathrm{~min}$ showed significantly higher Fos-LI density than control non-restraint isolation-reared rats in the frontal cortex (FC area 1, FC area 2), dorsal hippocampus (dCA1, dCA2, dCA3, dDG), the dorsal and lateral areas of the PAG (DPAG, DLPAG, LPAG) and the basomedial amygdala (ABM), central amygdala (ACe), entorhinal cortex and PVN thalamus (Table 1, Figs. 1 and 2). Restraint stress had no effect on Fos-LI expression in most ventral areas of the hippocampus and areas of the amygdala (vCA1, vCA3, vDG), lateral amygdala (ALa), $\mathrm{ABL}$ and $\mathrm{AMe}$ in isolation-reared rats given restraint compared to home cage isolation controls (Table 1).

In summary, restraint stress in isolation-reared rats 
increased Fos-LI density by about two or three times that seen in group-reared rats in the FC area 1, FC area 2, dCA2, dDG, LPAG, ABM, AMe and PVN thalamus. In contrast, group-reared rats exhibited a greater increase in Fos-LI density in the FC area 1, ABM and ACe with smaller increases in the ventral hippocampus and ACe. However, there was no difference in the response to restraint stress in the dCA1, dCA3, DPAG and entorhinal cortex between group- and isolationreared rats. These changes are summarised as increment ratios in Table 2 .

\section{The effect of PCA $(2.5 \mathrm{mg} / \mathrm{kg})$ administration on the} extracellular levels of 5-HT following isolation rearing

Basal extracellular 5-HT and 5-hydroxyindoleacetic acid levels in the dorsal hippocampus did not differ between group-reared and isolation-reared rats prior to drug treatment (Fig. 3). Mean values for basal extracellular 5-HT were $2.7 \pm 0.4 \mathrm{fmol} / \mu \mathrm{l} \mathrm{min}$ (group-housed control, $n=16$ ), $1.6 \pm 0.2 \mathrm{fmol} / \mu 1 / \mathrm{min}$ (group-reared, $n=10$ ) and $1.8 \pm 0.2 \mathrm{fmol} / \mu \mathrm{l} / \mathrm{min}$ (isolation-reared, $n=10)$.

Systemic administration of the PCA $(2.5 \mathrm{mg} / \mathrm{kg}$, i.p.) significantly increased 5-HT levels in the dorsal hippocampus in group-reared rats to about four times basal levels $(P<0.01)$, reaching a peak increase at $80 \mathrm{~min}$ post injection. In contrast, PCA given to isolation-reared rats had no significant effect on extracellular 5-HT (Fig. 3).

Table 2. The increment of Fos-LI density (cells $/ \mathrm{mm}^{2}$ ) from the basal level (control non-restraint) induced by restraint stress in various brain areas obtained from group- and isolation-reared rats

\begin{tabular}{lll}
\hline Brain area Group Isolation & $\begin{array}{l}\text { Increment ratio } \\
\text { between Isolation/ } \\
\text { Group }\end{array}$
\end{tabular}

\begin{tabular}{|c|c|c|c|}
\hline \multicolumn{4}{|l|}{ Frontal cortex } \\
\hline $\mathrm{FC}$ area 1 & 42.0 & 95.9 & 2.3 \\
\hline FC area 2 & 30.0 & 110.0 & 3.7 \\
\hline \multicolumn{4}{|c|}{ Dorsal hippocampus } \\
\hline CA1 & 0.6 & 0.5 & 1 \\
\hline $\mathrm{CA} 2$ & 0.3 & 0.9 & 3.0 \\
\hline CA3 & 0.5 & 0.4 & 0.7 \\
\hline $\mathrm{DG}$ & 0.2 & 0.5 & 3.1 \\
\hline \multicolumn{4}{|c|}{ Ventral hippocampus } \\
\hline CA1 & 0.6 & 0 & 0.3 \\
\hline $\mathrm{CA} 2$ & 0.8 & 0.2 & 0.3 \\
\hline $\mathrm{CA} 3$ & - & - & - \\
\hline DG & 0.3 & 0 & 0.3 \\
\hline \multicolumn{4}{|l|}{ Periaqueductal grey } \\
\hline DPAG & 3.3 & 3.2 & 1 \\
\hline DLPAG & 1.6 & 2.4 & 1.5 \\
\hline LPAG & 0 & 2.3 & 3.9 \\
\hline VPAG & 1.9 & 1.0 & 0.5 \\
\hline \multicolumn{4}{|l|}{ Amygdala } \\
\hline$A M e$ & 1 & 4.0 & 4.2 \\
\hline$A C e$ & 0 & 0.4 & 0 \\
\hline ALa & 0 & 0.9 & 2.2 \\
\hline $\mathrm{ABL}$ & 1.9 & 0 & 0 \\
\hline $\mathrm{ABM}$ & 0 & 1.5 & 2.9 \\
\hline Entorhinal cortex & 1.8 & 1.5 & 0.9 \\
\hline PVN thalamus & 1.2 & 3.7 & 3 \\
\hline
\end{tabular}

With the increment ratio, values above 1 indicate increased Fos-L density in isolates after restraint and below 1 decreased density.

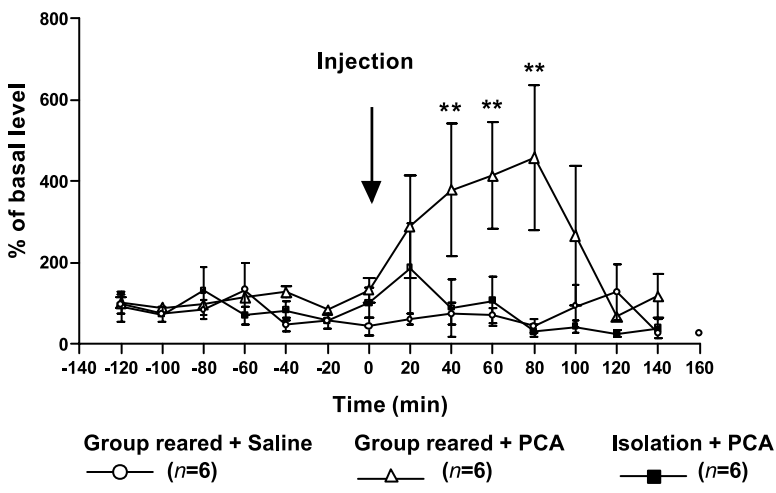

Fig. 3. Effect of saline ( $1 \mathrm{ml} / \mathrm{kg}$, i.p.) or PCA $(2.5 \mathrm{mg} / \mathrm{kg}$, i.p.) in group- and isolation-reared rats on basal 5-HT levels in the dorsal hippocampus. For clarity, only data from the group-reared salinetreated rats are given as there was no significant difference between these and isolation-reared rats after saline injection $(n=6 /$ group). Results are expressed as mean values \pm S.E.M. ${ }^{* *} P<0.01$ significantly different from saline-treated rats (two-way ANOVA, followed by Bonferroni post test).

The effect of acute restraint stress for 30 min on extracellular levels of 5-HT following isolation rearing

During the stress period, isolation-reared rats showed lower extracellular 5-HT levels compared to groupreared rats $(t$-test $P<0.05)$. However, after $30 \mathrm{~min}$ restraint, while both group-reared and isolation-reared rats tended to show an increase in the extracellular levels of 5-HT in the CA1 dorsal hippocampal area (Fig. 4), this was not significant (Fig. 4).

The effect of isolation rearing and mild footshock on hippocampal extracellular 5-HT

There was no difference between 5-HT levels in groupand isolation-reared rats ( $n=6$, both groups) prior to footshock (Fig. 5). Exposure to the testing box alone without footshock also failed to alter basal extracellular 5-HT levels in the dorsal hippocampus of either group-

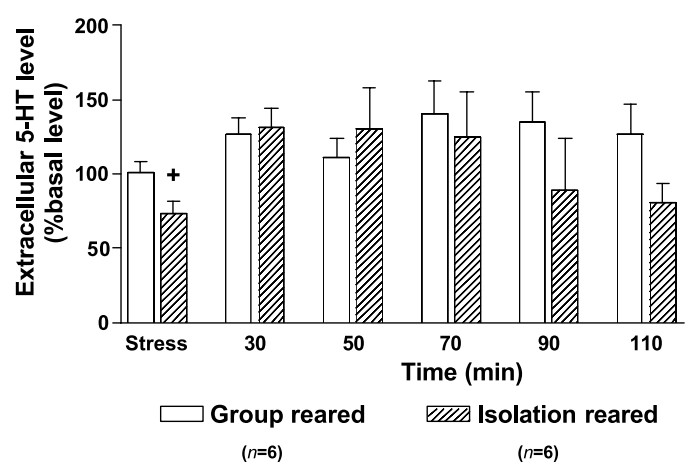

Fig. 4. Effect of acute restraint stress $(30 \mathrm{~min})$ on extracellular 5-HT in the dorsal hippocampus of group- and isolation-reared rats ( $n=6$ animals/group). Results are expressed as mean $\%$ of pre-restraint stress values \pm S.E.M. ${ }^{+} P<0.05$ significantly difference from group-reared rats (two-way ANOVA, followed by Bonferroni post test). 


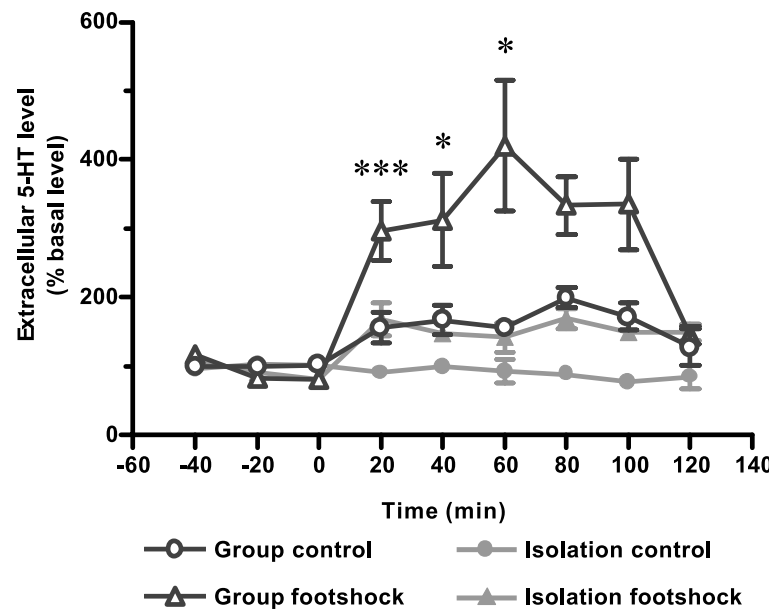

Fig. 5. Extracellular 5-HT levels in the hippocampus following footshock $(0.4 \mathrm{~mA}$ for $1 \mathrm{~s}$ every $\mathrm{min}$ for $10 \mathrm{~min})$. Extracellular hippocampal 5-HT was significantly increased by footshock in group- but not isolation-reared rats (two-way ANOVA, followed by Bonferroni post test). ${ }^{*} P<0.05,{ }^{* * *} P<0.005$ group- vs. isolation-reared rats, $n=6$ animals/group.

or isolation-reared rats ( $n=6$, both groups). However, inescapable mild footshock produced a marked increase in extracellular hippocampal 5-HT in group- but not isolation-reared rats (Fig. 5) at $20(P<0.005), 40$ and $60(P<0.05)$ min post footshock, with levels returning to normal by $120 \mathrm{~min}$.

\section{DISCUSSION}

Isolation rearing altered neuronal activity, indicated by the density of Fos-LI expression, in specific brain regions, including the dorsal and ventral hippocampus both under control conditions and in response to stress. In vivo microdialysis studies showed no significant difference in basal extracellular 5-HT in the dorsal hippocampus between group- and isolation-reared rats. However, while systemically administered PCA $(2.5 \mathrm{mg} / \mathrm{kg})$ caused a gradual and long-lasting increase in extracellular 5-HT in group-reared rats, this effect was not seen in isolationreared rats. Likewise, footshock produced a marked increase in extracellular hippocampal 5-HT in groupbut not isolation-reared rats and the response to restraint stress was also reduced by isolation rearing.

The optimal time for Fos induction in most brain regions is about $90 \mathrm{~min}$ after the beginning of the experimental period (Kellogg et al., 1998; Yokoyama and Sasaki, 1999) and this time was selected for the present experiment. In agreement with previous studies, c-fos mRNA was measurable in certain brain areas of control home cage rats. These regions included the cerebral cortex, hippocampus, thalamus (anterodorsal nucleus) and midbrain (Cullinan et al., 1995; Bonaz and Rivest, 1998; Chowdhury et al., 2000). The results from non-restrained animals show that isolation rearing alone alters neuronal activity, as indicated by a change in Fos, in the hippocampus (higher in vCA1) and amygdala (lower in the $\mathrm{ABL})$.
This effect of isolation may be due to a change in neuronal organisation or synaptic disarrangement in some brain regions as there is evidence that isolation rearing can cause neuroanatomical changes including reduction in neuronal and nuclear size in the occipital cortex (Diamond et al., 1975) together with a reduction in the number of cortical dendritic spines (Globus et al., 1973) and glial cells (Diamond, 1967). Rats housed in isolation from 40 days post birth showed a reduction of the synaptic contact zone and fewer perforated synapses in the medial amygdala (Ichikawa et al., 1993). Similarly, a reduction in synaptophysin immunohistochemistry (a marker of synaptic density) had been reported in hippocampal areas of isolation-reared rats (Varty et al., 1999). The maturation of the rat brain continues to occur after weaning, especially the hippocampal formation, which is not fully developed until about 35-40 days postnatal (Lanier and Issacson, 1977), and development of the dentate gyrus may continue throughout adult life (Kaplan and Bell, 1983, 1984). Neurotransmitter function also gradually develops in the rat reaching adult levels at 30-50 days postnatal (Coyle and Henry, 1973). In rats reared in isolation from weaning, brain maturation will occur while the animals are housed on their own. During this period the rats may lack essential sensory information and input from appropriate social contact, olfactory information and environmental stimuli for the normal development of brain structure and neurotransmitter function, resulting in altered behaviour in adult life compared to group-reared rats.

Previous studies have shown that acute restraint stress markedly increased c-fos mRNA expression in cortex, hippocampus, hypothalamus, septum and brainstem in the rat (Melia et al., 1994; Chen and Herbert, 1995; Kellogg et al., 1998; Martinez et al., 1998; Dayas et al., 1999; Yokoyama and Sasaki, 1999). Acute stress induced minimal or no change in the expression of c-fos mRNA in hippocampal regions (Cullinan et al., 1995; Senba and Ueyama, 1997; Bonaz and Rivest, 1998), while in the ACe both c-fos mRNA and Fos protein were induced following acute stress (Chen and Herbert, 1995; Cullinan et al., 1995), though others have reported no change (Senba and Ueyama, 1997). Severe stressors induced an increase in the expression of Fos protein in ACe, AMe and BLA (Chowdhury et al., 2000). Long-duration acute stressors induced lower Fos protein expression in the amygdaloid nucleus than short-duration acute stressors; possibly neurones may adapt to acute stress. In the present study short restraint stress $(10 \mathrm{~min})$ in group-reared animals increased Fos-LI density in areas of the cortex, hippocampus, amygdala and PAG. Thus, the amygdaloid nucleus is the major brain region responding to processive stressors. Isolation rearing altered the stress-induced change in c-fos expression with greater effects in certain brain regions and reduced responses in others. Thus, the mean Fos-LI density in isolation-reared rats after restraint stress was about two to three times higher than in group-reared rats in the $\mathrm{FC}$ area $1, \mathrm{FC}$ area $2, \mathrm{dCA} 2, \mathrm{dDG}$, DLPAG, LPAG, ABM, AMe and the PVN thalamus. 
In contrast, restraint stress reduced Fos-LI density in isolates compared to group-reared rats in the ventral hippocampus and ACe.

Importantly, the result of the present study showed that isolation rearing altered neuronal activity differently between the dorsal and ventral hippocampus. Isolationreared rats had significantly higher neuronal activity in vCA1 prior to stress but demonstrated a tendency for lower activity when exposed to stress while the opposite occurred in the CA2 region and dentate gyrus of the dorsal hippocampus. Moser et al. (1993, 1995) reported that damage to the dorsal hippocampus resulted in impairment to spatial memory, but this impairment was not found with ventral hippocampal damage. Moreover, Gentsch et al. (1999) lesioned the neonatal ventral hippocampus with ibotenic acid while leaving the adjacent areas intact and reported impairment in latent inhibition. Similarly, neonatal lesions also impaired pre-pulse inhibition post-pubertally (Lipska et al., 1995). These effects may be relevant to the disruption in latent inhibition and pre-pulse inhibition observed in schizophrenic patients which are taken as an indicator of deficits in information processing and in the ability to ignore irrelevant stimuli in these patients (Weiner et al., 1981). The Fos data, together with earlier morphological and behavioural data showing impaired pre-pulse inhibitory responses (Varty et al., 2000), indicate that disrupted hippocampal function might be important in the functional defects associated with isolation rearing. As serotonin has an important role in the response to stress, the next part of the study investigated the effects of isolation rearing on hippocampal serotonergic function using microdialysis.

PCA is an amphetamine derivative, which increases 5-HT release by a $\mathrm{Ca}^{2+}$-independent mechanism following entry into 5-HT nerve terminals through the selective uptake system (Marsden, 1996). In agreement with previous studies, PCA increased extracellular 5-HT (Adell et al., 1993) in the dorsal hippocampus of group-reared rats but no increase was seen in isolation-reared rats. PCA acts as a substrate for the serotonin transporter proteins and competes with the indole for transport into the neuronal cytoplasm. In addition, PCA has a lower affinity than 5-HT for binding to the cytoplasmic binding site of the carrier protein so 5-HT is transported in preference to PCA at low concentrations of PCA. We have previously found that the function of the serotonin transporter is not affected by isolation rearing (Muchimapura et al., 2002), indicating that the loss of the PCA response could be due to a decrease in the pool of releasable 5-HT, reduced synthesis (Jones et al., 1992) or enhanced feedback inhibitory tone. With regard to the latter, we have recently shown altered sensitivity of hippocampal 5- $\mathrm{HT}_{1 \mathrm{~B} / \mathrm{D}}$ autoreceptors (Muchimapura et al., 2002).

Restraint stress had no effect on dorsal hippocampal extracellular 5-HT in group-reared rats but reduced the levels in isolation-reared rats. Zhang et al. (1995) also found that acute restraint stress for $30 \mathrm{~min}$ did not change extracellular 5-HT in the dorsal hippocampus. In contrast, Vahabzadeh and Fillenz (1994) found that
10 min restraint stress induced an increase in hippocampal 5-HT release. There were differences in recovery time from anaesthesia after probe implantation between the two studies; in the former it was only $1 \mathrm{~h}$ but in the latter $12 \mathrm{~h}$. In the present study the recovery time was at least $12 \mathrm{~h}$. Kirby et al. (1997) also had recovery times of more than $12 \mathrm{~h}$ and reported no significant change in 5-HT in the hippocampus following restraint or immobilisation stress. The present restraint stress experiments were performed during the light period and Takahashi et al. (1998) showed that 5-HT was unaltered in the hippocampus by immobilisation stress during either the light or dark period but was increased in the striatum in the dark period.

Inescapable footshock is an uncontrollable stressor and combines processive with a physical stressor. In agreement with Amat et al. (1998), footshock in the present study markedly increased extracellular 5-HT in the hippocampus in group-reared rats while it produced no effect on isolation-reared rats. Footshock also increases extracellular 5-HT and serotonin metabolism in other rat brain areas, including the amygdala and prefrontal cortex (Dunn, 198; Heinsbroek et al., 1991; Kawahara et al., 1993; Yoshioka et al., 1995).

The present findings indicate that isolation rearing increases neuronal activation (c-fos) in response to stress in the dorsal hippocampus and frontal cortex. This suggests that reduced serotonergic tone may result in abnormal neuronal function under aversive conditions, which may explain the exaggerated response observed to novelty or stimuli predictive of danger. Furthermore, the presynaptic 5-HT release in vivo is altered by isolation as shown by the PCA data. Interestingly, restraint stress had no effect on 5-HT release in the dorsal hippocampus in group-reared rats while novelty, footshock and contextual conditioning increased hippocampal 5-HT release (Bickerdike et al., 1993). Together these results indicate that stress/aversive responses in the hippocampus are stimulus-dependent.

There is evidence that isolation rearing has a primary effect on the development of the cortex and hippocampus, resulting in secondary changes in other brain areas. For example, isolation enhances mesolimbic function (Jones et al., 1992), resulting in increased dopamine and 5-HT function in the striatum (Jones et al., 1992; Wilkinson et al., 1994; Robbins et al., 1996; Fulford and Marsden, 1998; Hall et al., 1998), but reduces hippocampal, serotonergic and noradrenergic responsiveness (Wright et al., 1990, 1991; Bickerdike et al., 1993). Changes in hippocampal formation following isolation rearing may trigger compensatory changes within systems that depend on normal hippocampal input using glutamatergic transmission. Thus changes in the hippocampus in neonates may cause functional reorganisation within the limbic system as a means of compensation. The nucleus accumbens receives glutamatergic innervation from the prefrontal cortex, amygdala and hippocampus (Christie et al., 1987). Prior in vivo studies showed that the hippocampus exerts potent modulatory control over prefrontal cortex afferent activation of neurones in the nucleus accumbens. The inhibitory action 
within the hippocampal excitatory circuitry might result in a failure of the efferent glutamatergic signal from the hippocampus to other areas of the limbic cortex and this may be pivotal in the neuronal dysfunction associated with disruption of pre-pulse inhibition in isolation rearing.

In summary, isolation rearing after weaning altered neuronal activity both in the resting state and when exposed to stress. These changes occurred particularly in the frontal cortex, amygdaloid nucleus and hippocampus. In the hippocampus, stress in isolates increased activity in the dorsal area but reduced it in the ventral compared to group-reared rats. Isolation rearing also reduced the effect of stress on serotonergic function in the dorsal hippocampus. Future studies should determine whether stress produces regional effects within the hippocampus. Overall the results demonstrate that early isolation rearing in the rat disrupts the hippocampal and cortical response to stress and support the view that isolation rearing is an experimental approach to understanding neurodevelopmental disorders.

Acknowledgements-We would like to thank C.H. Roe for expert technical support and also the Royal Thai Government for financial support to S.M.

\section{REFERENCES}

Adell, A., Carceller, A., Artigas, F., 1993. In vivo brain dialysis study of the somatodendritic release of serotonin in the raphe nuclei of the rat: effects of 8-hydroxy-2-(di-n- propylamino)tetralin. J. Neurochem. 60, 1673-1681.

Adell, A., Casanovas, J.M., Artigas, F., 1997. Comparative study in the rat of the actions of different types of stress on the release of 5-HT in raphe nuclei and forebrain areas. Neuropharmacology 36, 735-741.

Amat, J., Matus-Amat, P., Watkins, L.R., Maier, S.F., 1998. Escapable and inescapable stress differentially and selectively alter extracellular levels of 5-HT in the ventral hippocampus and dorsal periaqueductal gray of the rat. Brain Res. 797, 12-22.

Arnold, F.J.L., De Lucas Bueno, M., Shiers, H., Hancock, D.C., Evan, G.I., Herbert, J., 1992. Expression of c-fos in regions of the basal limbic forebrain following intra-cerebroventricular corticotropin-releasing factor in unstressed or stressed male rats. Neuroscience 51, 377-390.

Bickerdike, M.J., Wright, I.K., Marsden, C.A., 1993. Social isolation attenuates rat forebrain 5-HT release induced by KCl stimulation and exposure to a novel environment. Behav. Pharmacol. 4, 231-236.

Bonaz, B., Rivest, S., 1998. Effect of a chronic stress on CRF neuronal activity and expression of its type 1 receptor in the rat brain. Am. J. Physiol. 275, R1438-R1449.

Ceccatelli, S., Villar, M.J., Goldstein, M., Hokfelt, T., 1989. Expression of c-Fos immunoreactivity in transmitter-characterized neurons after stress. Proc. Natl. Acad. Sci. USA 86, 9569-9573.

Chaouloff, F., 1993. Physiopharmacological interactions between stress hormones and central serotonergic systems. Brain Res. Rev. 18, 1-32.

Chen, X., Herbert, J., 1995. The effect of long-term castration on the neuronal and physiological responses to acute or repeated restraint stress: Interactions with opioids and prostaglandins. J. Neuroendocrinol. 7, 137-144.

Chowdhury, G.M.I., Fujioka, T., Nakamura, S., 2000. Induction and adaptation of fos expression in the rat brain by two types of acute restraint stress. Brain Res. Bull. 52, 171-182.

Christie, M.J., Summers, R.J., Stephenson, J.A., Cook, C.J., Beart, P.M., 1987. Excitatory amino acid projections to the nucleus accumbens septi in the rat: a retrograde transport study utilizing $\mathrm{D}[3 \mathrm{H}]$ aspartate and $[3 \mathrm{H}] \mathrm{GABA}$. Neuroscience 22, 425-439.

Coyle, J.T., Henry, D., 1973. Catecholamines in foetal and newborn rat brain. J. Neurochem. 22, 425-439.

Cullinan, W.E., Herman, J.P., Battaglia, D.F., Akil, H., Watson, S.J., 1995. Pattern and time coutse of immediate early gene expression in rat brain following acute stress. Neuroscience 64, 477-505.

Dayas, C.V., Buller, K.M., Day, T.A., 1999. Neuroendocrine response to an emotional stressor: Evidence for involvement of the medial but not the central amygdala. Eur. J. Neurosci. 11, 2312-2322.

Diamond, M.C., 1967. Extensive cortical depth measurements and neuronal size increases in the cortex of environmental enriched rats. J. Comp. Neurol. 131, 357-364

Diamond, M.C., Linder, B., Johnson, R., Bennett, E.L., Rosenzweig, M.R., 1975. Differences in occipital cortical synapses from environmentally enriched, impoverished and standard colony rats. J. Neurosci. 1, 109-119.

Dunn, A.J., 1988. Changes in plasma and brain tryprophan and brain serotonin and 5-hydroxyindoleacetic acid after footshock stress. Life Sci. 42 , $1847-1853$.

Fulford, A.J., Marsden, C.A., 1998. Conditioned release of 5-hydroxytryptamine in vivo in the nucleus accumbens following isolation-rearing in the rat. Neuroscience $83,481-487$.

Gentsch, C., Bernstein, H.G., Becker, A., Hollt, V., Bogerts, B., 1999. Disruption of latent inhibition in rats with postnatal hippocampal lesions. Neuropsychopharmacology 20,525-532.

Globus, A., Rosenzweig, M.R., Bennett, E.L., Diamond, M., 1973. Effects of differential experience on dendritic spine counts in rat cerebral cortex. J. Comp. Physiol. Psychol. 82, 175-181.

Hall, F.S., Wilkinson, L.S., Humby, T., Inglis, W., Kendall, D.A., Marsden, C.A., Robbins, T.W., 1998. Isolation rearing in rats: pre- and postsynaptic changes in striatal dopaminergic systems. Pharmacol. Biochem. Behav. 59, 859-872.

Heinsbroek, R.P.W., Van Haaren, F., Feenstra, M.G.P., Endert, E., Van De Poll, N.E., 1991. Sex- and time-dependent changes in neurochemical and hormonal variables induced by predictable and unpredictable footshock. Physiol. Behav. 49, 1251-1256.

Ichikawa, M., Matsuoka, M., Mori, Y., 1993. Effect of differential rearing on synapses and soma size in rat medial amygdaloid nucleus. Synapse $13,50-56$.

Imaki, T., Shibasaki, T., Wang, X.Q., Demura, H., 1995. Intracerebroventricular administration of corticotropin-releasing factor antagonist attenuates c-fos mRNA expression in the paraventricular nucleus after stress. Neuroendocrinology $61,445-452$.

Jones, G.H., Hernandez, T.D., Kendall, D.A., Marsden, C.A., Robbins, T.W., 1992. Dopaminergic and serotonergic function following isolation rearing in rats: study of behavioural responses and postmortem and in vivo neurochemistry. Pharmacol. Biochem. Behav. 43, 17-35.

Kaplan, M.S., Bell, D.H., 1983. Neuronal proliferation in the 9-month-old rodent: Radioautographic study of granule cells in the hippocampus. Exp. Brain Res. 52, 1-5.

Kaplan, M.S., Bell, D.H., 1984. Mitotic neuroblasts in the 9-day-old and 11-month-old rodent hippocampus. J. Neurosci. 4, $1429-1441$.

Kawahara, H., Yoshida, M., Yokoo, H., Nishi, M., Tanaka, M., 1993. Psychological stress increases serotonin release in the rat amygdala and prefrontal cortex assessed by in vivo microdialysis. Neurosci. Lett. 162, 81-84. 
Kellogg, C.K., Awatramani, G.B., Peikut, D.T., 1998. Adolescent development alters stressor-induced fos immunoreactivity in rat brain. Neuroscience 83, 681-699.

Kirby, L.G., Alien, A.R., Lucki, I., 1995. Regional differences in the effects of forced swimming on extracellular levels of 5-hydroxytryptamine and 5-hydroxyindoleacetic acid. Brain Res. 682, 198-206.

Kirby, L.G., Chou-Green, J.M., Davis, K., Lucki, I., 1997. The effects of different stressors on extracellular 5-hydroxytryptamine and 5-hydroxyindoleacetic acid. Brain Res. 760, 218-230.

Lanier, L.P., Issacson, R.L., 1977. Early developmental changes in locomotor response to amphetamine and their relation to hippocampal function. Brain Res. 126, 567-575.

Linthorst, A.C.E., Flachskamm, C., Muller-Preuss, P., Holsboer, F., Reul, J., 1995. Effect of bacterial endotoxin and interleukin-1beta on hippocampal serotonergic neurotransmission, behavioral activity, and free corticosterone levels: an in vivo microdialysis study. J. Neurosci. $15,2920-2934$.

Lipska, B.K., Swerdlow, N.R., Geyer, M.A., Jaskiw, G.E., Braff, D.L., Weinberger, D.R., 1995. Neonatal excitotoxic hippocampal damage in rats causes post-pubertal changes in prepulse inhibition of startle and its disruption by apomorphine. Psychopharmacology 122, 35-43.

Marsden, C.A., 1996. The neuropharmacology of serotonin in the central nervous system. In: Feighner, J.P., Boyer, W.F. (Eds.), Selective Serotonin Re-uptake Inhibitors: Advances in Basic Research and Clinical Practice, 2nd edn. J. Wiley, Chichester, pp. 1-33.

Martinez, M., Phillips, P.J., Herbert, J., 1998. Adaptation in patterns of c-fos expression in the brain associated with exposure to either single of repeated social stress in male rats. Eur. J. Neurosci. 10, 20-33.

Melia, K.R., Ryabinin, A.E., Schroeder, R., Bloom, F.E., Wilson, M.C., 1994. Induction and habituation of immediate early gene expression in rat brain by acute and repeated restraint stress. J. Neurosci. 14, 5929-5938.

Morgan, J.I., Cohen, D.R., Hempstead, J.L., Curran, T., 1987. Mapping patterns of c-fos expression in the central nervous system after seizure Science 237, 192-196.

Moser, E.I., Moser, M.B., Andersen, P., 1993. Spartial learning impairment parallels the megnitude of dorsal hippocampal lesions, but is hardly present following ventral lesions. J. Neurosci. 13, 3916-3925.

Moser, M.B., Moser, E.I., Forrest, E., Andersen, P., Morris, R.G.M., 1995. Spatial learning with a minislab in the dorsal hippocampus. Proc. Natl. Acad. Sci. USA 92, 9697-9701.

Muchimapura, S., Mason, R., Marsden, C.A., 2002. The effect of isolation rearing on pre- and post-synaptic serotonergic function in the rat dorsal hippocampus synapse (in press).

Paxinos, G., Watson, C., 1986. The Rat Brain in Stereotoxic Coordinates. 2nd edn. Academic Press, New York.

Robbins, T.W., Jones, G.H., Wilkinson, L.S., 1996. Behavioural and neurochemical effects of early social deprivation in the rat. J. Psychopharmacol. 10, 39-47.

Rueter, L.E., Fornal, C.A., Jacobs, B.L., 1997. A critical review of 5-HT brain microdialysis and behavior. Rev. Neurosci. 8, 117-137.

Sagar, S.M., Sharp, F.R., Curran, T., 1988. Expression of c-fos protein in brain: metabolic mapping at the cellular level. Science 240, 1328-1331.

Schreiber, S.S., Tocco, G., Shors, T.J., Thompson, R.F., 1991. Activation of immediate early genes after acute stress. NeuroReport 2, 17-20.

Senba, E., Ueyama, T., 1997. Stress-induced expression of immediate early genes in the brain and peripheral organs of the rat. Neurosci. Res. 29, $183-207$.

Senba, E., Matsunaga, K., Tohyama, M., Noguchi, K., 1993. Stress-induced c-fos expression in the rat brain: activation mechanism of sympathetic pathways. Brain Res. Bull. 31, 329-344.

Stanford, S.C., Salmon, P., 1993. Stress: From Synapse to Syndrome. Academic/Harcourt Brace, London.

Stone, E.A., Zhang, Y., 1995. Adrenoceptor antagonists block c-fos response to stress in the mouse brain. Brain Res. 694, $279-286$.

Takahashi, H., Takada, Y., Nagai, N., Urano, T., Takada, A., 1998. Extracellular serotonin in the striatum increased after immobilization stress only in the nighttime. Behav. Brain Res. 91, 185-191.

Vahabzadeh, A., Fillenz, M., 1994. Comparison of stress-induced changes in noradrenergic and serotonergic neurons in the rat hippocampus using microdialysis. Eur. J. Neurosci. 6, 1205-1212.

Varty, G.B., Marsden, C.A., Higgins, G.A., 1999. Reduced synaptophysin immunoreactivity in the dentate gyrus of prepulse inhibition-impaired isolation-reared rats. Brain Res. 824, 197-203.

Varty, G.B., Paulus, M.P., Braff, D.L., Geyer, M.A., 2000. Environmental enrichment and isolation rearing in the rat: effects on locomotor behavior and startle response plasticity. Biol. Psychiatry 47, 864-873.

Weiner, R.D., Erwin, C.W., Weber, B.A., 1981. Acute effects of electroconvulsive therapy on brain stem auditory-evoked potentials. Electroencephalogr. Clin. Neurophysiol. 52, 202-204.

Wilkinson, L.S., Killcross, S.S., Humby, T., Hall, F.S., Geyer, M.A., Robbins, T.W., 1994. Social isolation in the rat produces developmentally specific deficits in prepulse inhibition of the acoustic startle response without disrupting latent inhibition. Neuropsychopharmacology 10 , 6172 .

Wright, I.K., Ismail, H., Upton, N., Marsden, C.A., 1991. Effect of isolation rearing on 5-HT agonist-induced responses in the rat. Psychopharmacology 105, 259-263.

Wright, I.K., Upton, N., Marsden, C.A., 1990. Resocialisation of isolation-reared rats does not alter their anxiogenic profile on the elevated X-maze model of anxiety. Physiol. Behav. 50, 1129-1132.

Yokoyama, C., Sasaki, K., 1999. Regional expression of Fos-like immunoreactivity in the rat cerebral cortex after stress: restraint and intraperitoneal lipopolysaccharide. Brain Res. 816, 267-275.

Yoshioka, M., Matsumoto, M., Numazawa, T., Togashi, H., Smith, C.B., Saito, H., 1995. Changes in the regulation of 5-hydroxytryptamine release by alpha2-adrenoceptors in the rat hippocampus after long-term desipramine treatment. Eur. J. Pharmacol. 294, 565-570.

Zhang, X., Kindel, G.H., Wulfert, E., Hanin, I., 1995. Effects of immobilization stress on hippocampal monoamine release: modification by mivazerol, a new alpha2-adrenoceptor agonist. Neuropharmacology 34, 1661-1672. 